\title{
Teacher Ethnographic Research as Epistemology: Using Ethnographic Research to Develop Reflexive Educators in Diverse Classrooms
}

\author{
Porfirio M. Loeza, \\ California State University, Sacramento \\ Margaret Roy \\ California State University, Sacramento
}

Arcy Devera, Ph.D.

California State University, Sacramento

Based on fieldwork, interviews and ethnographic research of student teachers, reflectivity is revealed as an important starting point for teachers working with diverse and multilingual students. Reflecting assist individuals as they attempt to assimilate a new cultural complexity, particularly one that is as complex as a classroom full of adolescents. Reflexive practices are essential to meet the learning needs in a multilingual, multicultural and global state. Ethnographic research can indeed provide a springboard into the development of reflective and reflexive educators.

"I thought that to be a fair teacher you had to be blind to culture, be blind to class because it was so important for me to treat my students equally. But now, and after that (anthropology of education) class, and now that I am teaching, I don't think like that at all."

-1 st Year Teacher

A myriad of questions arise as I ponder the complexity of teaching and learning in a multilingual, multicultural and global state. Can ethnographic research be epistemological? Is reflexivity enough, sufficient or even necessary when teaching in diverse classrooms? Maybe diversity is the problem and we all just need to "get along" and become more like the other. If so, who is the "other"? If the other is "them," then who are "we"? There was great hope when a group of university faculty in California envisioned applying the anthropology of education as a critical component in a major teacher preparation program. We wanted to take what was formally a typical multicultural course and replace it with what we hoped would become a critical course that focuses on the complexity of classroom and school culture. The major challenge has been teaching ethnographic research while doing a major ethnographic project over the course of a single fifteen week semester. There continues to be great hope as well as challenges.

The anthropology of education has been used since the 1950 's as a then budding field to understand the context of schools and classroom (Spindler and Spindler, 2000).

As in anthropology as a whole, the aim then was to understand the "other." This necessarily continues to be one of several authentic objectives in "doing ethnography" in schools and classrooms. The authors will posit in this paper that an equally authentic endeavor in the "doing of ethnography" is teacher professional development as they engage in the reflexive practices that are incidental when conducting ethnographic research. A reflexive anthropology displays tensions that include multiple cultural logics that are not just explained vis-à-vis each other but that are coconstitutive (Inda and Rosaldo, 2001). In short, a reflexive practice, whether in ethnography or in education, begins by being ideational but then becomes dialogic in a Bakhtinian sense and manages to provide what I will call mutually sustaining cultural logics. Culture, writ large, becomes the overarching signifier and nothing can exist outside of it. This last idea may at a certain level be completely nonsensical within anthropology but is so essential in education that a required core course in the "Anthropology of Education" was created to address this need.

Since 2004, the Single Subject Program that prepares middle and high school teachers (at California State University, 
Sacramento) has been using the anthropology of education as a required course in their teacher preparation program. Preservice teachers engage in ethnographic research with the intended objective of producing reflective and reflexive educators. Using discourse analysis and ethnographic interviews, this paper will explore the ethnographic research of two preservice teachers vis-à-vis their epistemological development as first year beginning teachers. My guiding questions are as follows: What is the relationship between teaching and learning the anthropology of education and beginning teacher professional development? Although reflexivity is arguably necessary when "doing" ethnography, is it sufficient when the reality is that most teachers in California and the U.S. are white-middle class females and will primarily teach in linguistically and culturally diverse schools and classrooms? I will triangulate the teachers' own ethnographic research with ethnographic interviews and participant observation in the teachers own classrooms. My unit of analysis will be temporal since I will compare the beginning teachers' ethnographic research with their first year teaching experiences a year after completing their ethnographic research and once each of them find themselves working in their own classrooms as first year teachers.

Teacher Ethnographic Research as Epistemology: Guidelines for Doing My Ethnographic "Hokey Pokey"

My own "hokey pokey" into ethnographic research was initially provided by the qualitative researcher Anne Haas Dyson and the anthropologist John U. Ogbu at the University of California at Berkeley. Much of my thinking in the following sections is influenced and attributed to them (Personal Communication, Dyson, 1997, 1998; Ogbu, 1997, 1998). Early in my teacher preparation course on the anthropology of education I provide a set of general guidelines that describe the entire process. I explain that a major goal of the course is to integrate a case study of a group of English Learners that is embedded into their classroom ethnography. Student teachers are then given the following assignment description as to what their ethnography should be:

A report or composition that provides a close examination of an individual classroom in a public school setting and demonstrates an ability to use anthropological approaches including field observation, data collection and analysis and the development and use of theoretical frameworks for understanding a classroom learning environment and a set of English Language Learners within that environment. The Ethnographic study is composed of a range of materials and artifacts and requires candidates to develop a field record in order to analyze and portray the classroom and the set of learners using a range of theoretical "lens" including minority status, cultural difference, and educational dynamics in formal and informal settings along with cognitive, pedagogical and individual factors affecting student's language acquisition. The best ethnographic studies will "tell the story of the classroom" from the perspective of learners and will thoroughly demonstrate the reflexivity of the educational researcher. With permission from the candidate, ethnographic studies will be made available to school site teachers in order to support their understanding of the nature of local classrooms.

I explain to my student teachers that a central requirement for their ethnographies will be that it include a focal group of English Learners. This is a historically underserved population in California and a programmatic decision was made during the current reiteration of the program that English Learners (i.e. students learning English as a second language) would play a focal role in our teacher preparation program. Students are reminded that we will be slowly unfolding the ethnographic drama throughout the course of the semester. Our experience has been that a few of the students have done this sort of painstaking work before but most of them have not. I tell students that they will have the feeling for quite a while of not being quite sure what they are doing and of also wanting to know everything immediately. I confirm that there is actually very little that can be done about this. They are told that they should try to enjoy the experience. My sense is that most of them do but there are a few who I would qualify as "resisters."

In each section of the course, I reassure students that their ethnographic projects are almost always interesting and successful. Almost always, moreover, I add that at the beginning people feel like "I didn't get anything good at my school [in terms of data]." Or, "my career is over and it hasn't even started yet." Or the more modest, "I'll flunk." I confirm that these are all normal reactions to a complicated but very interesting process. My experience has been that these feelings tend to dissipate after data analysis begins. Finally, I suggest that it is probably helpful to talk with other class members and even myself as the instructor for the course.

Students begin the ethnographic process by articulating a general research question. My goal is to get them to begin to think about their own particular educational interests in terms of particular situations or "events" that might merit close study. Early in the semester most questions are quite general. My suggestion is that is usually a mistake to rigidly define what their ethnographic focus will be too early in the semester. My sense is that it is fine to be quite vague as one begins the ethnographic process. I ask students that as they gain more ethnographic knowledge and the have more experiences and interactions from the field, their questions will need to become articulated in more precise language. The nature of their questions about the particular setting in which they are studying guides the particular data collection and analysis procedures that they will eventually use. A major 
piece of advice that I give them is that one does not do an ethnographic project to prove something that one is already convinced is true. One does qualitative/ethnographic research to understand something, not to prove something (Personal Communication, Dyson, 1997). In my course, we concentrate on understanding the tools we are using. I assume that their knowledge of their content area (i.e. math, science, social studies, etc.) will inform their projects, but I do not ask for direct references to their content areas.

Students begin by selecting a site and gaining entry. They are encouraged to be very low-key but friendly, and to minimize their interaction early in their fieldwork. Students are reminded that they are likely to feel rather awkward and ill at ease at first but that this is normal. Students are asked to visit the site as much as they can before they begin to formally collect data. This is sometimes not feasible since they have a full course load as part of their teacher preparation program. The expectation is that students will collect five separate sets of field notes (e.g., recording field notes, and transcribing as part of field notes, interviewing) over the course of four to six weeks. Student teachers are repeatedly reminded to think small. They then transcribe and follow the format suggested by Spradley (1980) comprised of note taking, note making and a reflective commentary at the end of each observations. In the next section I provide the full ethnographic text from each of two ethnographies completed by student-teachers that comprise this research. Each ethnography is followed by a detailed transcription of their respective interviews.

\section{Future Teachers' Ethnographic Research: Case \# 1 Discordant Goals: Mixed Messages in the Classroom}

Following the crowd of students, I entered the classroom of Ms. Mason for the first time on a Friday morning. Students pushed me through the doorway into a richly decorated science lab. Plush toy monkeys with long arms swung down from the ceiling on tendrils of climbing plants toward a skeleton that stood at attention near the teacher's desk. Rows of microscopes waited expectantly below posters with phrases like "Explore it!" on them, tacked up alongside colorful student work. "Patsy," a pale yellow corn snake, moved slowly around the edge of her case while the bearded lizard sat motionless watching the students chatting on the way to their tables. I felt excited to be in this classroom... and nervous. How was I going to be able to capture all of the interesting things that students would be doing in this room?

I soon discovered that it was not difficult to record the action in this room. In fact, there was very little that students did in this room beyond copying what was displayed on the overhead projector. In this extremely teacher-controlled environment, students seemed to navigate the teacher's mixed messages without much pause. The disconnection between the implied objectives of this science class and the actual objectives seemed only to bother me.

Virtually everyone that I observed ignored the inconsistencies and was conditioned to behave in the least "disruptive" way in this class. The teacher, receiving little resistance to her ways, continued in her pattern and I think felt that students were moving along in the class at a satisfactory pace. No one really raised concerns or questions about the material because these kinds of questions were not encouraged. The teacher thought students were engaged because they were quiet. Students, on the other hand, were accomplishing what was required of them for this class, in addition to a bevy of other illicit classroom behaviors. I saw that students didn't really care that they weren't learning; it was easier to "go with the flow" and move on with the day. The few who were really interested in science were thoroughly engrossed regardless of the actual material being covered. Everyone else understood how to navigate this class; they were just "getting through it."

The focus of my observations became evident quickly. I wanted to know: What is the relationship between goals projected and goals realized as it relates to the teacher designed space, teacher directions versus teacher actions and teacher reactions to student participation in discussions?

\section{Background}

In order to explore the perception and functionality of goals in Ms. Mason's class, we must understand the meaning of "goals" as it relates to this context. For the purpose of this paper, "goal" is defined as "an aim or result" ("Goal," 2006). To understand this classroom culture better, a brief discussion of goal theory as it relates to motivation is required. In the framework of the classroom, goal theory suggests that students or learners "direct their behavior" toward "mastery" or "performance" outcomes (Ormrod, 2006, p. 179). Mastery goals are aimed at gaining knowledge while performance goals are defined as "reflecting a desire to look competent in the eyes of others" (Ormrod, 2006, p. 179).

Within performance goals, there are subcategories of "performance-approach" (desire to show high-ability) and "performance-avoidance" (desire to avoid showing low ability) that can impact the overall success of learning in the classroom if they become the overarching marker of achievement (Kaplan, Gheen \& Midgley, 2002, p. 192). In this context, the focus by the teacher on one form of goals over another can be a decisive factor in determining the level of engagement in the academic content of the class. Instructional style, teacherstudent exchanges and environmental factors "are likely to establish different norms of behavior that would affect every student in the environment"depending on the teacher's intent in designing a mastery or performance goal atmosphere (Kaplan, Gheen \& Midgley, 2002, p. 194). In a performanceavoidance goal-oriented classroom, students are expected to participate at a minimum level. Students can appear "on task" but be engaged in other activities because there is low motivation to gain mastery skills in an environment that does not promote such values. 
A second implication of the nature of this classroom must be described for this ethnographic study. The teacherfocused environment of Ms. Mason's classroom extends to the framework for the case study of English Learners (EL). Ms. Mason was unaware that there were any EL students in this class period. In fact, she questioned that I was in the right room because she didn't think there were any EL students present. She made no accommodations in differentiating her instruction. Furthermore, she determined the students of focus for the case study. After obtaining a list of EL students in her class, I asked her to point out the students so that I could observe them. Out of my list of five students, Ms. Mason only showed me the first two students on the list.

Ms. Mason's ignorance of her EL students points to a "misconception"that Jim Cummins describes as an assumption that students' "adequate control over the surface features of English....is taken as an indication that all aspects of their 'English proficiency' have been mastered" (Baird, Berta-Avila, Lozano, McFadden, \& Mejorado, 2005, p. 180). The extent that Ms. Mason interacts with her students combined with Liberty Unified School District policies on English Learners could reinforce this misconception. At this school, students whose CELDT level is lower than "L3" are not in science classes. They have additional sections of English and math classes. This may not be the explicit policy of the district, but this is the practice at this school. Indeed, the district, and as a result, the school, emphasizes this misconception by regulating the course selection for L1-L3 English Learning students.

On a final note, it is necessary for the reader to appreciate the position of the observer. Just as the description of my interaction with Ms. Mason in showing me the EL students in her classroom indicates, my movements and level of participation within the classroom was severely restricted. It is important for the reader to recognize that this study is indelibly marked by the constraints placed upon me by the teacher in my capacity as researcher, observer and participant. Contact with students and my movement within the room was not encouraged nor was my presence ever explained to students. Avenues of exploration and participant-observation were invariably closed to me through implicit indicators from Ms. Mason. It was as if I was invisible. In another way, this is a positive trait of this study; I have no reason to think that the teacher performed differently when I wasn't in the classroom.

\section{Methods}

Site

This study takes place within a 7th grade Science classroom at Jaclyn Ryan Middle School in Old Oak Unified School District. The school is located in the heart of the "old town" area of Old Oak, California and is the oldest middle school in the district.

There are nine tables in this classroom and students face each other at tables of four. There are a total of eight lab stations located on either side of the room and at six of these stations, there are individual student desks. There is a large teacher desk and lab station at the front of the room in addition to a teacher computer station. There is an overhead projector and screen in one corner of the front of the room and a television with VCR/DVD player in the other. There is a double, sliding blackboard at the front wall of the classroom and a set of bookshelves in the back of the room. For additional details and a visual representation of the classroom, please refer to the classroom maps at the end of each entry of field notes.

\section{Participants}

The participants of this study are the 16 male and 16 female 7th grade science students, totaling 32 students. The science teacher, Ms. Mason, is female and white. The breakdown of "ethnicity" in this classroom according to the school is as follows: 14 responded "White," 7 responded "Hispanic," 3 responded "Asian," 3 responded "Pacific Islander," 2 responded "African American," 1 responded "American Indian" and 1 responded with "decline to state."

The students who emerge as a focal point to the study are: Cece, Nelli, Vicki, and Jimmy. In my observations before obtaining the student roster, I made some mistakes in my descriptions of students. Originally I mistook Cece's ethnicity for African American and Jimmy as white. Later, I learned that Cece is listed as "Pacific Islander" and Jimmy is listed as "Hispanic." As mentioned before, although there are five English Learners in this classroom, Ms. Mason selected the students in my case study. These students are Nelli and Vicki. The unidentified EL students are Shawn, Tony and Steve. All of the EL students are "L4" or "L5." Nelli is listed in the roster as "Asian" and Vicki declined to state her ethnicity. Nelli is Punjabi and her CELDT level is "L5." I was able to see Nelli outside of this class and she told me that she was born in the United States and spoke English before kindergarten. Vicki was difficult to approach because of the structure of the class and her shyness. I know neither her first language nor her cultural background but her CELDT level is "L4." My best guess is that she is Chinese but this is only a guess and an ill-informed one at best. More minor, but named students in the field notes are: Bei, Colin, Kevin, Scott, Mark, Susie, Jared, Jinny, Nicolette, Cara, Shawn (EL student), Sara and Ellen.

\section{Data Collection Procedures}

Data was collected and recorded in field notes over five separate visits to the same class and period of the day between the dates of February 24, 2006 and March 24, 2006. Four of the visits were approximately an hour in length and one visit was on a minimum day schedule of approximately half an hour. Ms. Mason's class began at 9:00 AM and ended at 9:56 AM, with the exception of the minimum day when class began at 9:00 AM and ended at 9:33 AM. In addition, there was one informal extended conversation lasting approximately 20 
Figure 1

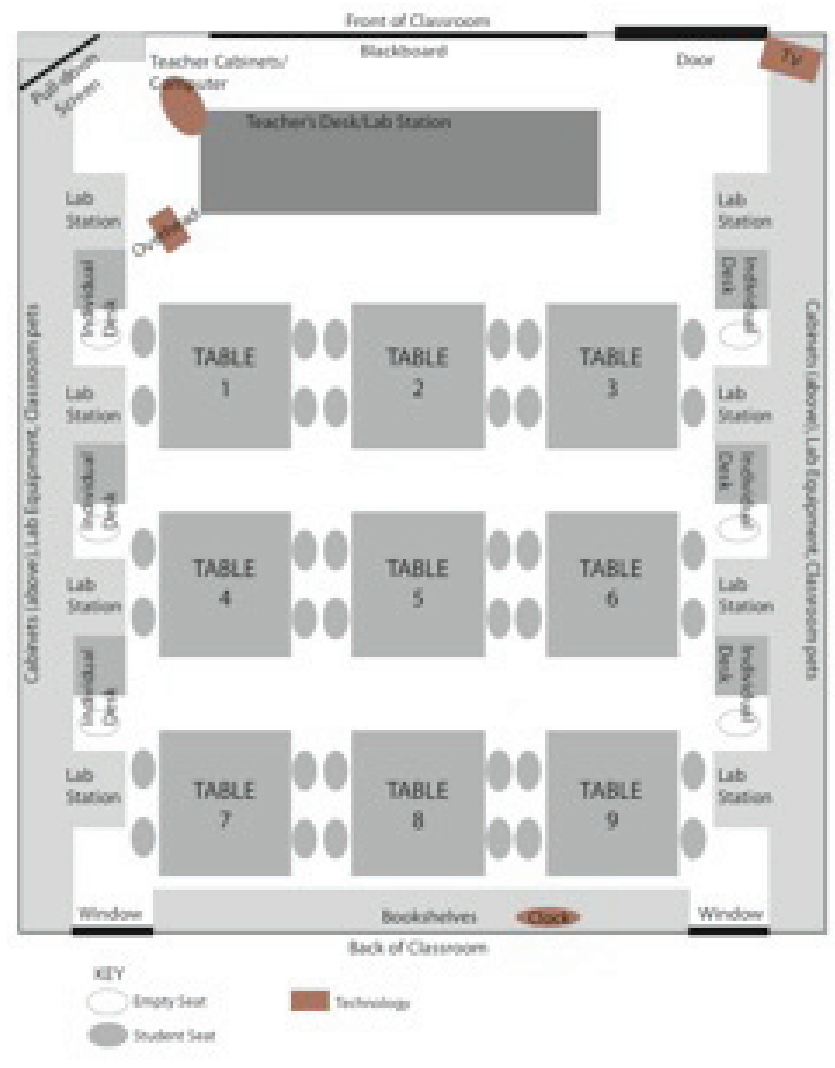

minutes with the EL student named Nelli before this class on March 24, 2006.

There were no official interviews with the teacher. Ms. Mason was not in her classroom before class started and I was given the impression that she didn't want to interact with me very much. Pieces of conversation are summarized in the field notes. There was also one conversation with the EL Coordinator for the school site in which I got a roster of the class with a listing of EL students and their CELDT levels. The first two observations did not have a focus so much as I was trying to capture as much dialogue and action as possible. The last three observations are more focused on the actions and dialogue of Nelli and Vicki, the two EL students I was watching for the case study. Also, in the last three observations, I tried moving around the room discreetly during "transition" times during the class so that I could observe both EL students. I also changed the location of my seat in some observations. Classroom maps were drawn for each visit and mark where the students of interest were located as well as my own location or movement throughout the period. All observations were recorded in a qualitative format.

\section{Data Analysis Procedures}

Most data was collected through visual and auditory means and was recorded in the "Note Taking" side of the field notes. As I was trying to record as much as possible, it was difficult to analyze "on the spot" and so I indicated items where I had questions and made the majority of my "Note Making" or data analysis afterward in the data transcription phase. As I transcribed my notes, I created categories of experiences related to the kinds of responses given by participants in student-student and teacher-student interactions. I also began organizing data into the kinds of messages being sent from the teacher to students and student reaction to those messages. When I noticed patterns of contradiction between these messages, I subdivided these segments into three final types of contradiction. 


\section{Findings}

In analyzing my observational field notes for Ms. Mason's Science class, I have found that there is generally a discordant relationship between the goals perceived and the goals actualized within the teacher-created culture of this classroom. This relationship can be seen through three main types of exchanges between teacher and students.

\section{The Affect of the Teacher-Designed Space Versus Teacher Instructional Style}

The intent of the teacher-designed space is in conflict with the teacher's instructional style that results in a restriction in student activity and movement. The choice of wall decorations, objects at the lab stations and the desk arrangement reflect a goal of exploration and cooperation. The choice of instructional delivery that ignores the choice of classroom aesthetics results in a goal of compliance.

After viewing other Science teacher's classrooms, I noticed a variety of student desk types. One room had traditional individual student desks in rows, facing forward; the Science room in which my cohort of student teachers met for class on this campus had individual student desks as well. Another Science room had long, narrow tables seating two to three students, facing forward. As seen in this section from the field note classroom maps, Ms. Mason chose large rectangular tables that could seat four students. The seats faced in toward the table from two sides so that students were facing each other.

\section{INSERT GRAPHIC}

Other aesthetic choices made by Ms. Mason were recorded on February 24, 2006:

"There are many posters of animals on the walls and there is a wall clock that says "2:00 p.m.." There are at least 5 hanging potted plants. Around the room there are various aquarium-like containers that house classroom pets consisting of a lizard and two snakes. There are many microscopes sitting on the counters toward the back of the room."

These choices are interesting in light of the teaching style of Ms. Mason. Much of the instructional content was delivered through teacher monologues. In my observations, there was only one instance of teacher sanctioned "group discussion" that was timed (by the teacher) for two minutes. Students were in their seats at almost all times and forced to be constantly twisted in their chairs so that they could face forward but also lean over the tabletop to write down notes from videos or the overhead projector.

In my visits, there were no activities observed that used any of the materials or resources of the room. No mention of the classroom pets or plants. No references to lab activities, microscope use or the skeleton (even when the students were covering bones and muscles). In my conversation with
Nelli, she told me that they looked through microscopes once and it was fun "cause they got to draw what they saw" but mostly they took notes. She said that it would have been "cool if she (Ms. Mason) had passed around bones" when they were learning them or if they could "touch animals." Nelli said that Ms. Mason told them they could do experiments (that are described in their books) at home for "extra credit."

Clearly the implicit message of the classroom aesthetics does not match the activities that the teacher directs. One would expect the room and teacher style to be in harmony because "the learning environment in a classroom [is] a reflection of the teacher's philosophy of teaching and learning" (Frank, 1999, p.42). This is not the case in Ms. Mason's classroom. You would expect the teacher in this room to have an open and collaborative tone by inviting students to explore many facets of scientific study. The reality is that the room and the teacher do not match. The room should have individual student desks that are in rows and face forward if the room were to match the instructional delivery most often utilized in this classroom.

These attributes of the classroom and the teacher instructional style indicate that Ms. Mason may be struggling with how she wants to be characterized as an educator. It strikes me that she may have internal conflicts between her love of science and a weariness of teaching within strict content standards that raise the pressure to cover a certain amount of material within a term.

\section{The Result of Teacher Contradictions on Instructional Sequence and Meaning}

The directions of the teacher often contradict teacher action in terms of the instructional sequence and meaning and consequently, students learn to physically appear "present" while mentally disengaging from the teacher commentary. The teacher's first statement often does not correlate with her actions and/or the teacher issues a secondary statement that is in opposition to the first. Consequently, students do not expect meaningful messages from the teacher and there is little motivation to become engaged in the teacher's dialogue.

For example, students were going to be taking a quiz on the morning of February 24, 2006 and the following took place:

Ms. Mason: Okay, 4 minutes to study. Get busy. (Ms. Mason starts timer.)

(Students start talking. Words heard: "tibia, clavicle, pelvis.")

(Some students are silent. Some are talking to one other person at their table. At some tables, everyone is talking together.) 
Ms. Mason: Okay guys; make sure you get the agenda. Assignment \#17 if we get to it, we probably won't.

\section{(Timer beeps)}

As you can see, Ms. Mason issued the second instruction about the "agenda" within the 4-minute time period she had set for students to study for the quiz. As the quiz began, Ms. Mason followed this pattern again, but through her actions. She explained "I'm setting the timer for fifteen minutes. If you do not finish you have to come at lunch or after school." At 9:17 AM, Ms. Mason said "Okay, 15 minutes." and started the timer. At 9:30 AM, when only 13 minutes had passed, Ms. Mason said, "Okay, all tests in. If you need more time, write that on your test and then turn it in." At 9:32 AM, the timer sounded and Ms. Mason walked over and turned it off.

I think what is hardest for the observer to understand is that not one single student objected to this injustice in the timing of the quiz. The students in this class are so conditioned to multiple, conflicting directions and actions from the teacher that they have learned how to sift through Ms. Mason's wording and actions to determine, as a group, what is expected from them. This group consciousness is formed out of a sort of social constructivism whereby students "gain better understandings than anyone could gain working alone" so that students appear on task (and sometimes are) but may be engaged in other activities (Ormrod, 2006, p. 19 \& 103). They have learned what to "tune out" and still appear "on task." In the 4-minute study session, students had grades at stake and were busy studying when Ms. Mason discussed the agenda. Students were focused on their own goal of test preparation so they ignored further commentary from Ms. Mason.

\section{The Impact of Teacher Responses on Student Participation}

When student participation is solicited in class-wide discussions, the teacher reactions are usually expressed in one of two ways: no validation of student response and/ or student response is related back to the teacher's own personal experience commentary which impacts the quality and frequency of student participation in active learning. When students offer compelling and topic related comments and anecdotes, Ms. Mason does not positively reinforce this student behavior and thus reinforces her preference for passivity in her students.

On March 16, 2006, Ms. Mason was discussing drug abuse and addiction. The following are two excerpts from the class-wide discussion:

(Ms. Mason asks a question. No one answers. Then 1 student says something. Ms. Mason begins to speak about club drugs.)
(Different student is called on and describes a related news story she saw.)

(Ms. Mason starts talking about undercover cops she knows.)

(Another student is called on and tells a story about being at a concert and seeing drug use.)

(Ms. Mason continues to talk about undercover cops and how they probably won't arrest you for marijuana unless you are causing a problem.)

Toward the end of this class period, this pattern was repeated but the implications of Ms. Mason's reaction are more severe. Cece, a student who usually "called out" without raising her hand and was often the object of teacher reprimand, raised her hand to speak and the following took place:

(Cece raises hand; Ms. Mason calls on her)

Cece: My cousin got expelled from school for selling and my other cousin was on drugs and my other cousin died...

(Ms. Mason: no visible response to Cece)

(Ms. Mason starts talking about how people will do anything to get drugs and get high and then tells a story about her friends who are prison guards. Tells about prisoners mashing up bananas or peanut butter to shoot up with.)

(Many students' voices heard. Some say "eweh! Why?")

Ms. Mason: "Because they'll do anything to get high..."

In the first situation, Ms. Mason is more involved in her own connections to the subject matter than in listening to the information that her students are giving her. She doesn't seem to use this as a way of understanding her students' prior knowledge and letting that help pace the kind and quality of the lecture-discussion. Ms. Mason's apparent inability to surrender her own stories for those of her students leads to an environment where students are implicitly told through Ms. Mason's dialogue: your stories, life experiences and questions don't matter.

In the last exchange, we can see that Ms. Mason is uncomfortable with the seriousness of Cece's intensely personal story. Rather than sensitively addressing Cece and 
making her story into a "teachable moment," Ms. Mason retreated into her own experiences rather than those of her students. Ms. Mason does not use what Haim Ginott termed, "congruent communication" (Ginott, 1972). By congruent communication, Ginott means a teacher should treat students with dignity, and use specific, harmonious language that reflects the student's feelings about him or her self and the situation (Ginott, 1972).

\section{Significance}

In discussing the lack of congruent communication within Ms. Mason's classroom, I realize how essential it will be for me to be reflective in my own teaching practices. As I studied this classroom and its participants, it became clear that the inconsistencies in messages stems from a sort of identity crisis on the part of the teacher. Ms. Mason is unsure of whether she wants her classroom to be an exploratory, student- focused place or a lecture, teacher-focused environment. She is unable to align her intentions with her practice and thus produces an off-balanced feeling in her room that leads to disengagement by her students.

The ramification of these contradictions, beyond their disengagement, is that students are not the origin of learning in this environment. Students' prior experiences are not valued nor used in planning instruction. Their "funds of knowledge" are not probed and used as a springboard for furthering the depth and quality of their education. Instead, Ms. Mason's "funds of knowledge" become the important indicator of the direction of instruction and students are unable to access meaningful learning.

In observing this classroom culture, it causes me to reflect upon the messages I send to students. In my own experiences and education as an artist and graphic designer, I have become sensitive to dissonant relationships between messages and the method through which those messages are delivered. In recalling the work of Marshall McLuhan and his communication motto, "the message is the medium,"I consider carefully the means I choose to send messages. The aesthetics of the space, the format of my syllabus, the arrangement of chairs, the organization of the progression of curriculum and my speech all reveal my overall vision for success in my class. Being a restricted observer in Ms. Mason's class reinforces the extreme importance of trying to thoughtfully craft the messages, explicit and implicit, that I send my students. If I do not identify my attitudes and beliefs about my own instructional style, I will sabotage my best intentions because it means that I am not evaluating those intentions against the reality of the climate of my classroom culture. If my thinking is muddled in how I plan to teach, students will see this lack of clarity and it will signal to them that "getting through" is preferable to actively participating.

One of the values that I bring to my classroom is the belief that all students are intelligent but rather are not always given the opportunities to best exhibit their intelligence because of uncreative teacher methodologies. Ms. Mason's style emphasizes for me that I must always strive to build my curriculum around student needs and capitalize upon their interests as a way to draw them into the study of art. This needs to be what drives the design and system of the content of my classes. If I do not recognize my students' strengths and areas of opportunity for growth, I am not meeting their needs in becoming a well-rounded, positively contributing member of society. This is not to say that my interests in art should not be exploited in letting students see my passion for the arts, but rather, my interests should be used to compliment the learning situation, not take center stage.

If I let student knowledge and interests guide the instruction, I can better address students who may be learning English and those with emotional, mental and physical challenges. I can better augment the content delivery to meet all of my students needs if I do not become too reliant on one model of instruction over another. By varying the kinds of learning activities and explorations, my students can experience the many modes of art: production, criticism, aesthetics, and history and together we can construct meaningful knowledge that pushes all of us forward in our critical thinking skills. This can only flourish if I train myself to respond to my students' needs by listening to their stories, understanding their questions and becoming involved in their learning. Using these insights can help me create an environment that correlates with sound teaching strategies that include students in the learning process and thus I am less likely to send contradictory messages about the goals of my class to students.

\section{Ethnographic Interviews: Case \# 1}

In ethnographic research, an embedded unit of analysis is always temporal conducted the following interview a year after Jennifer completed her ethnography. The setting was her own classroom and here's what she said:

LOEZA: "Let me take you back to the course on anthropology of education. What did you think was the goal?"

GRAVES: "I think (that the goal was to learn) how to approach your classroom of students from the outset. Trying to come in without too many judgments about your students but then also doing some investigative legwork about who they are and where they're coming from even before they walk (into) your classroom... And sometimes where they're going after... and taking that into consideration, not to say that you make excuses for students. You never do that. But you need to have a better understanding of who they are and where they're coming from so that you can connect your content better to their lives. I think what happens 
in reality is that those students that are redflagged, or I notice things with them, I then can use the skills from ethnography to find out more about them. Sometimes I think it's just really listening (to) the way they talk, as much as what they say... and listening to that body language and using that as a starting point for helping this kid fit into your class better or if there's something else going on outside."

In my other school, I have one student who lives in foster care and finds it difficult to deal with herself when she gets frustrated. She has particular outbursts in class and starts swearing. The ethnographic skills help me deal with her reality as I try to find ways to help my students:

LOEZA: "What are the biggest issues in terms of working with diverse students?"

GRAVES: "Keeping up contact with the home. When I was student teaching I had more time to make a call home or send an e-mail because I had less classes (to teach). Now I'm just in survival mode. I see myself now calling more for behavioral issues. At one school I get more contact by parents than at my other school. So I think keeping in touch with the home is a hard one."

LOEZA: "What is different in teaching art than teaching other content areas?"

GRAVES: "There is greater flexibility in teaching art according to the standards that in other content areas. There's always the element of choice when doing art. Even when everybody is doing the same project, there is choice as to how it is done. One good example is our discussion on popular art and to their individual life. I try to branch out in art and to connect it to their lives. Most art is greatly influences by western (European) art and I try to find pieces that connect to them such as when we did Aztec art."

LOEZA: "What would you like your students to take away from their time with you as they get older? Let's say ten years from now."

GRAVES: "What I would like my students to have as they grow up is to know that there is power in being able to create something with your own hands. Most of them come in thinking that they can't do art. They will even tell me that they can't do art. I think that's a powerful feeling to know that you can envision something in your head, get it down on paper somehow and actually create this object in three dimensions. I think this is powerful."

My biggest goal for my students as they get older is that art changes the way they see the worlds. That they actually see a pot, for example, and because they did it, they understand the complexity involved in doing that piece. My greatest hope is that they start to develop an aesthetic sense on their own and have opinions about visual culture and can back it up ...with evidence from what they see or know from their own experiences.

LOEZA: "What do you enjoy the most in teaching?"

GRAVES: "I love the problem solving part of it and that moment when they get it, and you can see them getting it, and they're excited that they got it, and you were actually there to see it. I know this happens like this in small ways all the time but you're not always there to see it when it happens. This part is exciting. And, I don't know, I go into a whole different mode when I'm teaching. I don't pay attention to anything about myself in particular. I'm very much in the present. All rest or parts of my day I'm focused about things in the future or things in the past. But when I'm teaching, I'm right there, all the way. Just being right there or just helping them see that they're really close to something and helping them see that they're really close to something ... that they needed just that little push to get the rest of the way...to help them see that they got the problem on their own."

LOEZA: "What do you hate about teaching?"

GRAVES: "All the outside not teaching stuff. In the classroom what I hate dealing with the most are discipline issues. That's not fun."

LOEZA: "How would you describe your classroom management style?"

GRAVES: "I'm not a super loud person, although sometimes I have to get a little bit louder. My classes are not very loud. I start my classes and my students take notes on what the behavioral standards are and what things look like in this classroom. I tend to be somebody who has a lot of procedural and organizational kinds of things that help things stay calm and that helps people know where they should be and what they should be doing. Part of it is routine and they come to expect certain things from me. I have the agenda and objectives written down. They understand that I'm 
around for help but that they should keep working because there is one of me and lots of them. Being as fair as you can be helps and (I) try to check in with my students a lot, particularly those that are at the end of the grade scale. It's all about improving themselves in the class. For me, it's all about having procedures and organizations. This helps me feel that I'm in control of things and they feel that I'm in control of things as well."

\section{LOEZA: "Anything else you would like to add?"}

GRAVES: "That I think that even if I'm not able to identify how my courses help me, I know they have. I think that sometimes right now because it's my first year I can't step back and look at it analytically. I know that it's all there and that it surfaces at different times and that it helps. I think that I'm so in the middle of it that it is hard to identify them but I know that they shape how I approach things."

\section{Future Teachers' Ethnographic Research: Case \# 2 Teaching Style and Student Motivation}

"Society is made of people's reciprocal relations with each other. Equity, justice, and respect are necessary in order for people to have positive relationships. The strife for this social norm, however, is often abandoned at the foot of the classroom."

One English Learning classroom in particular, displays inequity as the teacher's formal authoritarian teaching style stifles students' agency. In turn, students that lack this agency and self-autonomy begin to lose, if not already have lost, intrinsic motivation to carry on tasks without supervision.

Tao, Peter, and Saheed are students in Ms. O's class. Tao, for the most part, is obedient, Peter is a jitterbug, and Saheed likes to talk. Though all three students vary in manner, one thing is definite-all of them are on task when Ms. O overlooks the class. However, the moment that Ms. O is preoccupied or is not present, most of her students, including Tao, Peter, and Saheed, are unable to manage their tasks independently.

For some reason, Ms. O had to leave the classroom. As for every Friday, students are to get into their reading groups, and then they read assigned books aloud to their group peers.

Ms. D, the student teacher, has been a part of the class for some time now therefore she assumed the students knew the routine. She tells them to get into their groups, pick a book, and read aloud. All the students got up from their chairs and moseyed into their groups, but thereafter, half of the students did not know what to do next.

Tao, who usually picks out a book for her group first, was in this case the first one to say, "I have no clue what to read." When one of her group members suggested a book, she responded, "This is the boringest book ever." About ten minutes of class has elapsed by now.

All the while, Peter is continually throwing a pencil up in the air and catching it. Ms. D was across the room dealing with another dilemma that she was unaware of his behavior. Peter continued to throw the pencil higher and higher. At the opposite corner, Ms. D was handling a girl crying. It seems that her group members taunted her by saying that she is "in 8th grade" and that she "should know how to read this." Her feelings were hurt and she sat with her face on the table sobbing. As time went on, the girl simply sat there with her head on the desk.

Saheed read aloud for the whole entire class period. None of his other group members bothered to take turns. The two female group members also continued not to listen to him. Finally, the class period was ending so the student teacher tells them to pack up. This routine, however, does not bypass them because at five minutes to the bell, all of them had their backpacks on and were ready to go.

Ms. $\mathrm{O}$ is on her way back which is made visible by her shadow on the right window. She has to come all the way around to the opposite side to the door. Suddenly, a student yells out, "be good, be good, here she is." Immediately, the entire class took their backpacks off, sat there quietly, and waited for Ms. O to burst through the door.]

The students are aware of how to act when Ms. O supervises them. They understand that they need to "be good" for Ms. O. Conversely, their purpose of acting "good" when Ms. $\mathrm{O}$ is watching dissipates when she is not present. Without Ms. O's authority, the class becomes chaotic. The students are used to having this grandiose presence of order hovering over them that when it is suddenly taken away, they break and lose their composure. Even Tao who is usually on task loses her responsibility as a class member. Peter who acts against his urges to throw pencils when Ms. $\mathrm{O}$ is present is not able to self-contain his actions, or even worse, he is not aware of the way he is behaving.

Thus rises the question of the relationship between teaching style and student agency as it relates to motivation. It seems that the students are conditioned to act accordingly to Ms. O's authoritative rule, which can be an effective way to learn, but to what extent can the students begin to think about their actions for themselves. Their intrinsic motivation to carry on tasks without supervision is hindered and replaced by external and continuous reminder of how they should act and work properly. Background:

The classroom teacher, Ms. O, uses a formal authoritative teaching style wherein she tends to "focus on content. This style is generally teacher-centered, where the teacher feels responsible for providing and controlling the flow of the content and the student is expected to receive the content."1 This type of teaching style does not allow much student

1 http://members.shaw.ca/mdde615/tchstycats.htm 
participation and opinion sharing during class time. Thus students do not build personal relationships with one another nor do they build one with the teacher.

The classroom culture in Ms. O's class is a weary one. The students do not know each other's names. It is safe to assume that they do not know much about each other's background as well. Although they do work in groups, the students get each other's attention by either tapping each other and/ or calling at each other with "hey." It also seems that when students formulate and asks questions that are not to the teacher's liking, they are easily dismissed. Ms. O covers a significant amount of information, therefore it seems that she has to time to divulge outside the agenda.

This classroom has a richly diverse demographic. There are about forty percent Latino/Latina, thirty seven percent Asian/Pacific Islander, thirteen percent Middle Eastern and ten percent Russian/Ukrainian students in the classroom. Most of them, if all, are fluent in their mother tongue. Most of them have parents who speak little or no English at all. Ms. O stated that parent phone calls are hard to manage because of the language barriers.

The classroom does not allow students to speak in their native tongue. They are immersed in the English language. Most of the students still have strong accents, which is very pronounced when they read aloud in their groups. Furthermore, the classroom curriculum does not appeal to their diverse background. The class work mostly consists of silent reading, journal writing, and grammar. The students are engaged in grammar. There are many students who are willing to answer when the teacher asks for volunteers to correct grammatical errors on sentences. The students usually do grammar where Ms. $\mathrm{O}$ is at the front of the class for fifteen minutes of the fifty minutes they have of the period.

Ms. O stands in front of the classroom where there is an overhead projector between her and the students. The classroom desks are set up in a $U$ shape configuration. At the top where the U- desk ends is her lecture point. Ms. O's desk is in the back of the class. She has counters in her classroom where she keeps her own coffee maker. On the bottom of the counter, she has the classroom pet bunny. The pet is inaccessible to the students. The classroom reflects her authoritarian teaching style. The desks do not easily maneuver in a group formation. This is, however, a great set up for lecture based class since every one has easy access to see the teacher.

In a more macroscopic level, Dewey Middle School is diverse as well. Most of the students are middle class status. It is a fairly new school. They reopened the school in 20042005 school year and are still going under renovations. There are not many resources available for English Learning students. There is less resource available for parents. There is a community center about a mile and a half away from the school. The Dewey Community Center offers basic counseling for EL parents. Like Dewey Middle School, the surrounding neighborhood is relatively new and unfinished.

Bring this back into Ms. O's classroom, the students do not have access to vent their frustration as an EL student. They are not encouraged to speak up in class. Although they all can identify being from different cultures, the classroom culture does not embrace this aspect of their growth. It is a cut and dry class, which by all means, is effective in teaching the students grammar and syntax, but is lacking the environment for holistic learning.

\section{Method \\ Sites and Participants}

The classroom observed is an integrated class of sixth through eighth grade students with level three or below English language competency. The classroom is located in $\mathrm{K}-1$ portables just on the outskirts of the cafeteria. Ms. $\mathrm{O}$ is currently attending University of California, Davis to earn her masters degree. The students are coupled in this particular group for most or more than half of their classes. The EL students are mainstreamed in one point of the school day. Tao is a Chinese- American immigrant, Peter is half Chinese, halfJapanese student, and Saheed is a Middle Eastern student who is also a language learner in his native tongue. Although, Tao, Peter, and Saheed are the main students followed, this ethnographic study primarily looks at the teacher's teaching style and how this affects all of her students' motivation to learn without supervision.

\section{Data and Procedures}

For about seven weeks, I observed Ms. O's class every Friday during fourth period. I was one of the two observers that visited Ms. O's classroom during the same time frame. I would sit primarily behind the students. This position gave me a wide spectrum of the room; I was close enough to overhear conversations yet far enough to be unnoticed. I also collected data by interviewing two students, Tao and Christina during their lunchtime. Tao and Christina invited the other observer and I to walk around Dewey campus. In that intimate setting, I had the privilege to observe Tao and Christina's daily lunch routine, the cafeteria, where many of Ms. O's students ate box lunches, and the blacktop, where students often played games. Tao also shared what she liked and disliked being in middle school and more importantly, in Ms. O's EL class.

\section{Data Analysis and Procedures}

In order to prevent my biases from spreading all over my observations, I divided my observations according to the notemaking and note-taking sections. ${ }^{2}$ In Frank's Ethnographic Eyes: A Teacher's Guide to Classroom Observation, she teaches the student teacher to take unbiased and exact notes

2 Frank, Carolyn (1999). Ethnographic Eyes: A Teacher's Guide to Classroom Observation. Heinemann: Portsmouth, NH. ISBN 0-325-00201-0. 
with a time frame included. In every observation, the time is progressive and the notes are split into those two sections. I did not dissect my observation until after I have made all my observations. However, I did experience my "aha" moment, I tried not to focus on that subject too much because I felt as if it would tint the rest of my observation. When all my observations were in tact, I carefully reread all of them threading related information together. What I found out in my observation is that started to focus my discussions based on Ms. O and her relationships with her students. Why is Ms. O's relationship so formal with her students? Why did I feel distant to her even as her colleague? Thereafter, my theories about her authoritarian teaching style started to formulate. As I started taking on that standpoint, my observations made it more than clear that there is definitely a connection between her teaching method and students' behavior-more specifically, their intrinsic motivation.

\section{Teaching Style: A Direct Link to Student Motivation}

[Side Note: The three assertions to follow are direct reflections of my thoughts and progress. Thus, each assertion is interconnected by idea as well as time.]

\section{Claim One}

The authoritarian teaching approach is a teachercentered way of learning. This method invites most of students' attention to focus on the teacher. Although Ms. O gains the attention in the classroom, the reciprocal backfire of this method is disconnection with her students.

[Ms. O sits on the curb with her arms crossed and waits for her class to line up properly. She is wearing gloves, turtleneck, and a vest since the weather is cold outside. She tries to make eye contact with the students who keep moving around in the furthest back of the line. She continues to wait until they are silent until she lets them inside the classroom. The students earned five minutes of free time from the previous days, but that gets taken away from them. Ms. O reviews the school rules and then further proceeds to give examples of what she saw that violated this.

They are now ready to work. Ms. O poses the question, "how can we make the environment better?" The students are to write a quick write on this subject. Not one minute later, Ms. $\mathrm{O}$ is telling some of her students to improve their penmanship. She further tells other students to sit up properly in their chairs. When Saheed starts to talk to Tao, Ms. O head over to them and asks Saheed what he is inquiring about. She explains to Saheed the task at hand and waits for him to understand. Everyone is quiet and writing.

As Ms. O starts to walk around again, Saheed shouts out, "I have a question! What is in a hotdog?" Mrs. O asks him right back, "why are you asking me this?" Saheed turns his head back on his paper and begins to write. Ms. O continues to move about and occasionally scolds Peter to finish his work.

After twenty minutes, Ms. O stands in the front of the room and asks for some students to share. The class is ill responsive and Ms. O gives out some examples. Saheed comments, "I think we need flowers to make our school nice look." Ms. O expands his thoughts and tells the students that some of the classes around school are growing tomatoes. Saheed gets excited and begins to explains, "In Pakistan, we had plants, different plants, and my friend..." Ms. O cuts Saheed's thoughts and reminds the class that they need to write down the agenda and their homework before class ends.

Ms. O writes the following on the board: reading, new vocabulary, silent reading. Students are writing while she gives out directions. No one has their hand up, talking, and all of them are writing on their school calendar. Saheed and Tao are writing with their heads lowered into their notebooks as the bell rings.

When Ms. $\mathrm{O}$ is in front of the classroom, she commands attention in every way: eyes, ears, body, and mind. Her class time is well spent, always succinct and never divergent from her agenda. As one will observe, there is barely any time for any of her students to be off task. When Peter is not working, she makes sure that he gets back to the worksheet. The students are constantly on their toes to make sure they are on her "good" list. The students are told to sit upright, better their penmanship, and not to ask silly questions. Each student understands when Ms. O is not happy with his or her behavior. All in all, this classroom sounds like a "perfect" classroom.

From a distance, one would agree with all that is mentioned in the description above. However, let's think about Ms. O's effort in keeping her class in such a manner. Ms. O has to ensure that her class is on task by constantly scrutinizing each student's every move. The students do not learn how to behave on their own. Ms. O spends a massive amount of energy to restrain her students from acting like people. Students are, in the first place, people who need relationships with their peers. When Saheed had a question to Tao, Ms. O cuts this opportunity for a peer learning and takes it upon herself to answer his question. Students learn mostly from each other in corporate learning.4 Perhaps, Tao would have had an opportunity to recap what she learned if she were to explain her answer to Saheed. Instead, Ms. O asserted her position as authority to answer Saheed.

Tao did not even need to further explain or assert her own opinion. It seems that if Ms. $\mathrm{O}$ is the one stating her opinion, there is not a need to battle or agree. It is simply left as is. To clarify this thought, let's use another example: Saheed has a question about hotdogs. On the surface level, his comment is inappropriate in the context at hand since the students are writing about "how to better the environment." Yet, it seems that his concern is legitimate as he asks this question with fervor and without laughter or sarcasm. In context, his question does pursue some sort of acknowledgement from Ms. O. Hotdog ingredients are an abundance of unhealthy material for our bodies, thus it correlates with the waste that 
we pollute our very environment. Saheed's abstract thinking is hindered by Ms. O's abruptness to silence his thoughts.

Perhaps to take this even further, one can safely assume that the depth of class discussions in this EL classroom wades on the surface level of thinking. Ms. O's persistence in keeping to her agenda limits divergence of the students' critical thinking. Critical thinking skills students acquire through questioning and linking similar ideas are hindered by the strictness of Ms. O's agenda. Neither Tao nor Saheed question her authority or her logic. Are we fostering students who are incompetent to voice out a difference of opinion?

Lest not forget that Ms. O's class is also an EL classroom. Most of the students in this classroom are not fluent in English and they do often shy away from public speaking due to many factors like their accents and low self esteem caused by culture clashing. In such a classroom where their language acquisition is level with their peers, this should be a safe and inviting atmosphere for them to practice their verbal ability with each other.

Summing all of these factors together, the overall underbelly of Ms. O's classroom culture is one that is tight knit in curriculum but does not serve students holistically. The classroom is rich with ethnic diversity with students from all backgrounds, yet their curriculum does not reflect nor incorporate this diversity in their learning. Ms. O appeals to their cognitive thinking but she does not promote emotional and cultural development. The lack of intimacy in her classroom is detrimental in building relationships. She scolds, punishes, and shuts her students down quickly and easily because she has no personal relations with them. Ms. $\mathrm{O}$ is disconnected with her students and likewise, her students are disconnected with her. In fact, the students are disconnected with each other. They barely know each others' names and background. We will explore this notion further as students move into group work where Ms. O's time and focus is split between groups. It is then that the disconnection in the classroom relevant and becomes a barrier to their education.

\section{Claim Two}

In a teacher-centered-authoritative classroom, students are conditioned to perform and please the authority, which in this case is the teacher. Students' intrinsic motivation to perform tasks for their own benefit is replaced by "acting" to get reinforcement from the authority. Furthermore, the students' disconnection within their peers and teacher promotes performing/acting in the classroom.

[Ms. O assigns each student in a group. In their groups, students are to get in circle formation, choose a book, take turns reading it aloud, and come up with a group summary of their reading. There are five groups in all. Saheed is in a group with three female students. Tao is in a group of two male and three female students with herself included. Peter has the same gender operation as Tao.

The students were given a minute to get into their groups.
Because of the desk arrangement, three groups were on the ground while the other two used tables and chairs. From Ms. O's angle in the front of the room, two of the groups on the ground were out of sight hidden away by the desks.

Ms. $\mathrm{O}$ is walking around making sure that the students are on task. It takes her five minutes to get every group settled and going and thereafter she stands in the front of the class. Saheed's group is one of the groups on the ground out of sight. In about a minute that Ms. O stopped walking around, Saheed starts to read aloud without his group. His group tells him to "stop reading like that." Saheed ignores them and yells out "finish" after he was done. One of the female student in his group shouts for him to "shut-up" and calls Saheed a girl.

All the while, Ms. O has two of her male students at her desk for punishment. She has them read aloud to her since they refused to listen and work in their groups. They do so accordingly. Peter's group continues to talk about other matters besides the book at hand. When Ms. O released the students by her desk, she becomes free to walk about. She immediately heads over to Saheed's group. Saheed and the female student stops arguing and start reading in their group. Ms. O even asks Saheed what the book is about and he responds, "parents." As Ms. O leaves Saheed's group to talk to Peter's group, Saheed and the female student starts to quietly argue again.]

From the very beginning, Saheed's group is doomed to falter as a group. In middle school, students work better in same gender groups or equal ratio of female and male students. Ms. O places Saheed in an all female group. His group wasted fifty minutes arguing rather than getting an education. Perhaps, Saheed was displaying a behavior from being the outcast of the all female group. It would be a fallacy to assume that Ms. O was unaware of the gender dynamics in Saheed's group. Nonetheless, her lack of consideration for Saheed reflects her disconnection with her students.

It is not, however, Ms. O whose the sole blame. All of the students in Saheed's group lacked consideration for each other. They had no investments towards their own and each other's education because they did not have interconnection within the group or the class. When Ms. O was not around to ensure that they stay on task, they do not have intrinsic motivation to carry out the task of reading for themselves. Saheed, like most of the students in the classroom, see no benefit in learning their lesson. They worry more about getting punished with Ms. O.

For example, the two male students that were punished had to read in front of Ms. O. it was only then, when they were in trouble with Ms. O that they"acted" to avoid being punished. When they went back into their groups, their behavior was not altered. This goes the same for Saheed's group. When Ms. O stepped into their group, they all performed for her. Saheed started listening to the female he was arguing with and the female student stopped inferring her opinion and got on task. This "acting" pleased Ms. O that she soon left their group. Yet, 
their behavior transitioned back to the latter when they had no authority to perform to.

The groups are working harder when Ms. $\mathrm{O}$ is at their space. They become or pretend to be engaged with their readings. Ms. O has the power to motivate her students to work. They aim to please her and that is rewarding if she is available to each group. Conversely, the student's intrinsic motivation to learn diminishes as Ms. O's authority and presence fades. The students' lack of intrinsic motivation in learning is not the only aspect that calls for concern. Another consideration is their lack of motivation and respect towards their classmates.

Referring back to claim one, students are disconnected with each other because they are restrained from forming relationships with one another. As like the example of Ms. O stepping in when Saheed asked Toa for help, students rarely have the space to work with each other. The lack of communication and relations is reflective in the student's inability to work successfully in groups. The students are kept to work individually; therefore they have no prior play in working with each other. The female student telling Saheed to "shut-up" and Saheed not knowing what to do in working with female group members is indicative towards the flaw in authoritarian teaching method.

The students are conditioned to perform not only in doing work but also in working with each other. Saheed and the female student stopped arguing when Ms. O stepped into their circle. It was then that they were on task and learned about the book that they were reading. The two group members "acted' to get along only to have Ms. O leave their space. The minute that she left, they were back to being in natural position. The question thus far is to inquire what the students are being taught. They are learning to please the authority rather than understanding the benefits of actually learning. Their motivation to "want" to learn wilts and the motivation to "act' for authority takes precedence.

\section{Claim Three}

Students mimic the teacher's actions and interactions since the teacher models how to act in the classroom. Ms. O's authoritarian style attracts attention to herself, holds the power in the classroom, and disconnects her with the students. Thus, her teaching style motivates her students to act accordingly, wanting power over their peers since they rarely assert their opinions in the classroom.

[The student teacher, Ms. W, is trying to get a student on task. She repeatedly asks this student to do his work. She tells him, "Do you know that I expect you to work on the character list?" He responds, "Well, I expect you to get me a piece of paper." ${ }^{\prime 3}$ ]

For the reason that authoritarian teaching style is teacher-centered and promotes individualistic learning,

3 Observation 6. November 18, 2006. Forth Period students learn to impose their opinions without considering others. In this EL classroom, Ms. O is the authority. In this case, we see that Ms. W does not get the same respect as Ms. O. The student clearly does not "act" accordingly when asked to do the following task. Why might this be? If students aim to please authority, why does Ms. W have a harder time getting the students to do their work? The answer to this question lies within the first claim. Remember when Saheed asked Ms. $\mathrm{O}$ about the hotdog, she completely neglected his thought process and moved on. Here, the situation mimics how Ms. $O$ deals with her students. The student teacher asks the student to do his work, and the student shuts the student teacher down without considering her emotions.

In fact, the student in this example is trying to gain the authority from the student teacher. Notice how he mimics the same words that the student teacher uses. The student does not respond in a respectful manner but commands her to "get [him] a piece of paper" as if he were the authority. Again, we must ask why do students rebel and act in this fashion? In this classroom, it is scarce for students to state their opinions or influence their curriculum. They are, in a way, unable to speak and express their feelings. This brings about frustration and tension in the classroom. At the very least, students are starting to rebuttal in passive aggressive ways such as challenging the next authority figure next to Ms. O. They also try to overthrow their peers to gain some sort of power and control in the classroom. [Tao is arguing with her group. She keeps saying, "na-uh. This is the boringest book ever." The next group over to Tao's group is also arguing. The group is targeting one female student telling her that she is "eighth grade, you should know how to read this." She starts to cry with her head down on the desk. Saheed's group is off task, and Peter continued to throw his pencil. ]

In what seems to be a chaotic display of students misbehaving, the situation is actually inevitable and controlled. Each student in each group is trying to gain the authoritarian role since in group-work Ms. O cannot continuously assert her control. The students are challenging each other rather than working cooperatively in groups. The students even go as far as hurting their peer's feelings to get the feeling of power. Their intrinsic motivation to get the task done is lacking because their energy is focused in either asserting their power or defending their control. They also spend their energy in "acting" for the authority, which leaves the students barely any motivation to work by themselves.

\section{Conclusions}

There is hope in that students are trying to rebel against the oppression of power. They do so in a chaotic way, but the fact that they are trying to gain power for themselves is admirable. These EL students have to go through so much trying to balance the dualistic nature of abiding by the English language and their native tongue. Why not give them the freedom to speak in the classroom rather than take 
this safe zone away from them? These students are working within the same level of language acquisition that naturally, the class should be inviting for them to practice their language speaking skills. The authoritarian teaching method may work in other classrooms such as college, but for now, these students just need engagement with literature and the English language to help them improve.

If this were my classroom, I would first incorporate a more open and diverse curriculum. My lesson plans would promote bilingualism. They would further promote embracing all of the rich culture present in the classroom. It is such a privilege to work with students from all background, and this I would not ignore. Second, I would encourage students to network within themselves. In order to be successful, they also need to learn how to cooperate with other people who are different from them.

Again, I stress building relationships. I want my students to become familiar with me. I will not hesitate to tell my students my own values of life. The students, however, do not need to know whom I am dating or the hobbies I'm into, but they should get a sense of what l've come to care for. In turn, I should connect with each individual student on this deeper level too. By the end of the first semester or trimester, I should be able to understand their individual beliefs and cultures as well. To achieve these relations with my students, my lesson plans need to incorporate aspects of self-searching in my assessment. Although students and teachers can connect on a superficial basis, I am striving for that deeper connection-a soul searching-knowing how I would think-how they would think kind of way. I don't know how realistic this goal may be, but I want to be on that level with my students where they would fully understand my non-verbal communication.

In addition to everything, my students need to learn self-responsibility in the classroom. One way to achieve that is to have a set agenda that is routines for students to do in the beginning of the class. Another way is to place responsibility on the students to tell me what assignments they are either missing or having trouble on. This will be hard, but conditioning students by being available whenever they need help is key. Being helpful outside of class time teaches students the importance of asking for help on their own time. As much effort as they are going to put in will be as much (and more) effort I will put out to make sure they achieve their goals.

My classroom will be an intimate classroom. I will learn my student's names and they will learn each other's as well. I link self-growth with students' cognitive development, therefore, the more the classroom caters to their self-growth, the more they are able to focus and learn from my lessons. Again, I want my students to succeed outside the classroom. My definition of success goes far beyond earning a living. I want my students, when they leave my classroom, to be worldly and thinking outside of themselves.

\section{Ethnographic Interviews: Case \#2}

Similar to the teacher in the first case, I conducted and open ended ethnographic interview of the second teacher. The following is a selective transcription:

LOEZA: What did you think I was trying to do with the anthropology course?

MARIA: Well, it helped me in my (beginning teacher support) training. They asked us about the gender of your students, what is the background of your students, what is the class differences in your students. And it's just helpful to know the background. It's helpful for me to know who can't even provide a pencil. It comes down to that critical (level). It helps me understand my students. Everything I do, even like today, you will see that we'll work on an essay for students who have divorced parents. Because the novel that we're reading talks about a character whose parents got divorced and had a lot to do with his foundation and so we're writing something about that. A lot of my students come from divorced families and that's something that even I have to find out. So, the background is very important.

LOEZA: So, if I asked you to visualize in a cultural sense your biggest cultural challenge, what would that be in relation to the kids you have this year?

MARIA: Culturally speaking this classroom that you're about to observe is primarily not of minority students. There are some that are Chicano and Latino. There are some that are Afro-American but the majority of my students are not.

LOEZA: Because I worked with you for a full semester and you submitted all kinds of work to me, I have a sense of you as having a critical perspective on race theory and the way race functions in this society. How do you see (that) other teachers at this school see that (issue) in relation to you?

MARIA: You know, can I be really honest? (Is) That okay? I hope this doesn't offend any of the teachers here. I am a minority teacher here. I am a Filipino. I think a lot of my background served, especially because I was an immigrant, served, like, helps me understand everything. The teachers that work with me they know that they're Caucasian and they're very aware of the privilege that they have. For some reason, they're very open-minded and I can talk to them about these types of issues like the achievement gap, the cultural differences. 
And surprisingly, they make lesson plans when we collaborate that are culturally rich as well. I don't know if the students can relate as much to them, however. Is that what you're asking?

LOEZA: In part, that's what I'm asking. I was at this school in 2002 and, although I have not looked at the data, the demographics of the school feel different.

MARIA: In what sense?

LOEZA: It was more white five years ago than now.

MARIA: You know what it is? It's the influx. They're starting to build low cost housing here. A lot more duplexes, a little more condo type houses and apartments. And there is a big influx from the bay area (referring to the San Francisco bay area). So from Oakland there are a couple of my friends who have moved to Dewey and Liberty (the Greater Sacramento area). There's just this influx because the bay area is so expensive. They come here and that's why it changed.

LOEZA: What did you think you did not get in your teacher preparation program that you think you should have gotten?

MARIA: Hmmm. That's a hard one. A lot of it had to do with my mentor teacher that I was paired with. But the class really did cover a lot of classroom management issues which was good. I think that I wasn't ready for the performance level differentiation. I'm still having an issue (with this). Like, a lot of my minority students, their performance level is ultimately as a majority lower than some of my other students who are Caucasian. Their intelligence level is way up there, or their performance level, sorry, I mean, is way up there. And so the problem that I have is that I don't know how to challenge those students that are way above while trying to pull up the students without leaving them behind the students that are performing really well. I'm still having issues with that.

LOEZA: Now, thinking back, why do you think those differences exist?

MARIA: Honestly, I work in the system of education where test scores (matter) and, depending on what a child does, it correlates with a grade. I think it has to do a lot with cultures too. A lot of cultures, their culture's behavior doesn't mean that they sit there for two hours and read whatever instruction is given to them. These things are different in the home. So when they come here, students have to change their mentality, the way they act in order to be successful here. Because I know that my students who cannot focus and sit down to do readings and all that stuff, if I do any games of activities that involves movement, that involve some sort of, I don't know, some type of response, or call out loud, they're the first to call out and participate. And they do so well. But the minute that I tell them to do an essay, they can't sit there for two hours and do it. That's where they are.

LOEZA: What did you think before you took the anthropology course?

MARIA: I thought that to be a fair teacher you had to be blind to culture, be blind to class because it was so important for me to treat my students equally. But now, and after that class, and now that I am teaching, I don't think like that at all. I'm a little more lenient to students that I know come from a difficult family background, who I know come in here and don't even have a backpack. Like I said, when I know this, I'll stand at the door and have a pencil ready and I pass it to that kid.

LOEZA: Beyond a pencil, is there anything else that you do?

MARIA: Yeah, I call parents all the time, especially parentswhohavesingleparenthouseholds because it's hard for them to check on their (children). And they don't have internet or whatever, like that kind of stuff. I call them at work and I make sure that they're on task. None of my kids are failing because I'm really anal. I'll go to the bus stop and go hunt a kid and bring them into my classroom before class and make them do homework. Stuff like that.

\section{Triangulating Between Discourses: Changing the Way Student-Teachers See the World}

Art serves as a perfect metaphor for the anthropology of education. "My biggest goal for my students as they get older is that art changes the way they see the world."This was Jennifer Graves's rejoinder when I asked her what she wanted her high school art students to take away from her class. As an art teacher, she was indeed referring to art but in many ways this is also the inherent goal in teaching the anthropology of education. Many future teachers come with an aesthetic and differential valuation of cultures. I also wish that my students, as a professor of the anthropology of education, leave my class 
with a greater appreciation for the diversity of cultures since each culture provides direct evidence for multiple answers to similar problems. I also want the anthropology of education to "change the way they see the world." In the next section, I will discuss the relationship between teaching this course and aspects of teacher professional development. I will also discuss discourse elements between the student teacher's ethnographic research, interviews carried out during their first year as teachers and my own classroom observations in their respective classrooms.

Relationship Between Teaching and Learning the Anthropology of Education and Beginning Teacher Professional Development

Structural Considerations in Beginning Teaching vis-à-vis Substantive Issues.

A major tension in beginning teacher professional is what is known in teaching as classroom management. In a cultural sense, the expectation in U.S. schools is that teachers have full "control" of the behaviors that students display in the classroom. This basically means that most (if not all) students appear to be engaged in what, again, appears to be a teacher directed objectives. This is often referred to in the field as "being on task." Off-task behavior is to be shunned upon and should be avoided. There is evidence in each of the two ethnographies that future teachers are preoccupied with structural issues such as classroom management. The first teacher, Jennifer, for example, uses terms such as discordance, dissonance and congruence. Even in her own classroom, as a first year teacher, she mentions this when she says, "I tend to be somebody who has a lot of procedural and organizational kinds of things that help things stay calm and that helps people know where they should be and what they should be doing. Part of it is routine and they come to expect certain things from me." At a surface level, it could appear that both ethnographies are about structural aspects related to classroom management. At a deeper level, however, they are not, particularly when you juxtapose them with the teacher interviews.

There is evidence in both ethnographies and in the teacher interviews that the student-teachers continuously grapple and oscillate between the structural aspects of teaching and what I would call more substantive issues. In each of the ethnographies, at a surface level there is evidence that each student teacher is grappling with those structural issues. The structuring of classroom life is a central responsibility of all teachers in a cultural sense and each ethnographic case reflects this tension. In the first one, for example, Jennifer clearly reacts against her mentor teacher's rigidity in style while in the second ethnography Maria refers to it as an issue of motivation. Nevertheless, the core of each ethnography deals with more profound substantive issues. Using Jennifer's own words from her interview, she says that an aspect of ethnography has to do with "how to approach your classroom of students from the outset. Trying to come in without too many judgments about your students but then also doing some investigative legwork about who they are and where they're coming from even before they walk (into) your classroom."

Maria, the second case, also grapples with the structural aspects as a first year teacher while dwelling into those more profound substantive issues. As an English teacher, she uses a culturally diverse literacy canon. She struggles in her ethnography with issues of student-agency, power, performance and what in education would be called a teacher-centered curriculum. (Teacher centeredness alludes to a disproportionate focus during instruction on the teacher as oppose to the students.) Maria continues to struggle with these issues in her own classroom as a now first year teacher. She is fully cognizant of the consequences of a teachercentered curriculum but also understands that the "culture of teaching and learning" requires that she appear in control of the learning environment. My sense is that this will continue to be a source of positive tension for her. Ethnographic Discourse, Educational Discourse and Ethnographic Stance.

As part of my research for this paper, I visited each of my former student- teachers' classrooms. They were now in their first year as full time teachers in their respective classrooms. Jennifer, the first case, is an art teacher working at two different high schools and Maria is a middle school English teacher. At a surface level, both teachers were primarily employing what I will call the discourse of education. They would refer in both their interviews and during my visits to their classrooms to topics such as lesson plans, lesson development, standards and lesson differentiation. These topics are well within the discourse of education and essential components of the culture of teaching. It is, however, the ethnographic stance that continues to be in evidence during their first year as beginning teachers.

Each teacher's ethnographic stance is displayed during their interview. Jennifer tells me that "you need to have a better understanding of who they are and where they're coming from so that you can connect your content better to their lives." Recall that this was a major source of ethnographic dissonance in Jennifer's own research. She called it "discordant" or "sending mixed messages." She then adds in her interview, "Sometimes I think it's just really listening (to) the way they talk, as much as what they say." It is in listening that we allow other cultures to penetrate us. Often, as teachers in K-12, there is little of this type of "listening," notwithstanding a culturally embedded type of listening.

\section{Reflexivity in Teacher Ethnographic Research}

One major critique that many student teachers have of their teacher preparation programs is that they are always reflecting. In fact, I recently recall that one of my current students wrote in one of his entry journals that he was actually required to complete five separate reflections in five out of 
his seven classes. He was not disagreeing with the value of reflecting per se but whether this could not be somehow connected at the program level into fewer reflections. Student teachers do indeed see the value of reflecting but my sense is that they are looking for a "concrete answer" for this complex cultural practice that we call teaching. Although most teachers are reflective, only a few are reflexive. There is evidence that ethnographic research provides an initial springboard towards a reflective and reflexive teaching practice, one that includes the "teacher" and "student" in a mutually constitutive and dialectical understanding of each other. As first year teachers, both Jennifer and Maria have a reflexive ethnographic stance that began with their own ethnographic research and continued in their first year of teaching.

Based on the fieldwork, interviews and ethnographic research of student teachers for this paper, there is a sense that reflectivity is not enough but it is a starting point for teachers that will end up working with diverse and multilingual students. The two ethnographies began by asking the basic ethnographic question - What's going on here? A second major ethnographic issue becomes - What do I call it? This refers to the analytical language that one uses in understanding a given social situation. Again, Jennifer uses analytical terms such as discordant, mixed messages, and implied versus explicit objectives as she grapples with her ethnographic case. In turn, Maria uses terms such as teaching style, student agency and performatives as she discusses her situation. Reflecting is indeed a starting point for all individuals as they attempt to assimilate a new cultural complexity, particularly one that is as complex as a classroom full of adolescents.

If the promise of ethnographic research is to provide reflexive educators, Jennifer and Maria have far exceeded that pledge. They began by understanding the murky waters of ethnographic research. All along the way they continuously reflected and began to build a language of analysis in their field notes. They repeatedly went back to the field and came back with more questions. They acted, interacted and transacted with their participants.

\section{Conclusion}

Jennifer, the art teacher, tells me that once her high school students grow up, she would like for them to "know that there is power in being able to create something with your own hands. Most of them come in thinking that they can't do art." The art in ethnography has to do with going out in the field, taking notes and then trying to put them together into some type of ethnographic report. In this sense, both teacher- ethnographers did this well though they both continue to grapple with their current reality as they work through their first year in the classroom. Mostly, they continue their reflexive practices. Maria, for example, tells me that she finds it difficult to deal with the "performance level differentiation." This alludes to being able to teach your subject matter to students that have different levels of content knowledge. This is a very difficult issue to address even for "experienced" teachers. Yet, it is further evidence of the reflexive practices that are essential as teachers struggle to meet the learning needs in a multilingual, multicultural and global state. Ethnographic research can indeed provide a springboard into the development of reflective and reflexive educators.

\section{REFERENCES}

Baird, Berta-Avila, Lozano, McFadden, \& Mejorado (Eds.). (2005). Bilingual Education: Introduction to the Education of English Learners ( $p$ 180). Boston: Pearson Custom Publishing.

Frank, C. (1999). Ethnographic Eyes: A Teacher's Guide to Classroom Observation (p. 42). Portsmouth: Heinemann.

Ginott, H. (1973). Teacher \& Child: A Book for Parents and Teachers. New York: The Macmillan Company.

"Goal" (2006). Compact Oxford English Dictionary. AskOxford. com. Retrieved April 30, 2006, from http://www.askoxford. com/concise_oed/goal?view=uk

Kaplan A., Gheen M. \& Midgley C. (2002). British Journal of Educational Psychology Classroom Goal Structure and Student Disruptive Behavior Vol. 72, No. 2, June 2002 (p. 192, 194). EBSCO Publishing. Retrieved April 30, 2006, from http:// proxy.lib.csus.edu/login?url=http://search.epnet.com.proxy. lib.csus.edu/logi n.aspx?direct=true $\& d b=a f h \& a n=7167037$

Moll, L.C., Armanti, C., Neff, D., \& Gonzalez, N. (1992). Funds of knowledge for teaching: Using a qualitative approach to connect homes and classrooms. Theory into Practice, 31 (2), 132-141.

Ormrod, J. E. (2006). Essentials of Educational Psychology ( $p$. 19, 103, 179). Upper Saddle River: Pearson Prentice Hall.

Inda, Jonathan and Rosaldo, Renato. (2001). Anthropology of Globalization: A Reader. Blackwell Publishing.

Spindler, George. (2000). Fifty Years of Anthropology and Education 1950-2000: A Spindler Anthology. Lawrence Erlbaum. 